Research Paper

\title{
VEGF-C Gene Polymorphisms Increase Susceptibility to Rheumatoid Arthritis
}

\author{
Chengqian Dai ${ }^{*}$, Shu-Jui Kuo ${ }^{2,3 *}$, Sung-Lin Hu' ${ }^{2,4}$, Chun-Hao Tsai ${ }^{2,3}$, Yuan-Li Huang5, Chien-Chung \\ Huang ${ }^{2,6}$, Lihong Wang ${ }^{1}$, Guohong $\mathrm{Xu}^{1}$, Chen-Ming Su${ }^{7 凶}$, Chih-Hsin Tang ${ }^{2,5,8}$ \\ 1. Department of Orthopedics, Affiliated Dongyang Hospital of Wenzhou Medical University, Dongyang, Zhejiang, China \\ 2. School of Medicine, China Medical University, Taichung, Taiwan \\ 3. Department of Orthopedic Surgery, China Medical University Hospital, Taichung, Taiwan \\ 4. Department of Family Medicine, China Medical University Hsinchu Hospital, Hsinchu, Taiwan \\ 5. Department of Biotechnology, College of Health Science, Asia University, Taichung, Taiwan \\ 6. Division of Immunology and Rheumatology, Department of Internal Medicine, China Medical University Hospital, Taichung, Taiwan \\ 7. Department of Biomedical Sciences Laboratory, Affiliated Dongyang Hospital of Wenzhou Medical University, Dongyang, Zhejiang, China \\ 8. Chinese Medicine Research Center, China Medical University, Taichung, Taiwan \\ *Equally contributed as first authors \\ $\square$ Corresponding authors: Chen-Ming Su,PhD, E-mail: proof814@gmail.com; Chih-Hsin Tang, PhD, E-mail: chtang@mail.cmu.edu.tw \\ (c) The author(s). This is an open access article distributed under the terms of the Creative Commons Attribution License (https://creativecommons.org/licenses/by/4.0/). \\ See http://ivyspring.com/terms for full terms and conditions.
}

Received: 2019.03.06; Accepted: 2019.07.17; Published: 2019.09.20

\begin{abstract}
Vascular endothelial growth factor C (VEGF-C) promotes angiogenesis, a prominent feature in rheumatoid synovitis, contributing to the perpetuation of the global burden of rheumatoid arthritis (RA). VEGF-C gene polymorphisms predict the risk of developing various human diseases, such as urothelial cell carcinoma, oral cancer and coronary artery disease. We sought to determine whether single nucleotide polymorphisms (SNPs) of the VEGF-C gene can predict the risk of RA. Our study recruited 210 patients with RA and 373 healthy controls between 2007 and 2015, and performed comparative genotyping for SNPs rs7664413, rs11947611, rs1485766, rs2046463 and rs3775194. In analyses adjusted for potential covariates, we found that compared with subjects with the A/A genotype of SNP rs 11947611 , those with the $A / G$ genotype were $40 \%$ more likely to develop RA (adjusted odds ratio [AOR] 0.61; $95 \%$ confidence interval $[\mathrm{Cl}] 0.40$ to $0.92 ; p=0.02)$. In addition, subjects lacking the $A / A$ genotype $(A / G, G / G)$ of SNP rs2046463 were more than twice as likely as those with the $A / A$ genotype to require methotrexate (AOR 2.23, 95\% Cl 1.25 to 3.98; $p=0.01$ ), while those who lacked the $G / G$ genotype $(G / C, C / C)$ in the SNP rs3775194 had a significantly lower risk of requiring prednisolone as compared with those with the G/G genotype (AOR $0.39,95 \% \mathrm{Cl} 0.19$ to $0.79 ; p=0.01$ ). Our findings suggest that VEGF-C gene polymorphisms might serve as a diagnostic marker and therapeutic target for RA therapy. Pharmacotherapies that modulate the activity of the VEGF-C gene may be promising for RA treatment.
\end{abstract}

Key words: single nucleotide polymorphism, rheumatoid arthritis, VEGF-C

\section{Introduction}

Rheumatoid arthritis (RA) is an autoimmune disease that manifests hypertrophy and hypervascularity in synovial tissues and leads to joint destruction, affecting approximately $1 \%$ of the global population [1-4]. Despite several treatment regimens emerging in recent years that have enabled a substantial portion of RA patients to achieve disease remission with minimal symptoms, some patients remain treatment-refractory and continue to experience progressive joint deterioration and increasing functional limitations, or even premature mortality [5-7]. When compared with the general population, RA patients face higher risks of major morbidities, including infection and pulmonary and renal disease, and an approximate 1.5-fold higher risk of mortality [8]. The fact that genetic factors account for around $60 \%$ of the overall susceptibility to RA highlights the importance of research into the genetic basis for RA [5, 9]. Research into RA genetics may facilitate risk prediction and enable individually 
tailored treatment $[6,10]$.

A single nucleotide polymorphism (SNP) is a variation in a single nucleotide occurring at a specific site in the genome [11-14]. Comparisons of SNP distribution frequencies among patient populations (e.g., patients and controls) are commonly applied to predict disease risk and prognosis, including RA [15, 16]. For instance, polymorphisms of the vascular endothelial growth factor C (VEGF-C) gene can predict the risk and prognosis of various diseases, including urothelial cell carcinoma, oral cancer, and coronary artery disease [17-19].

VEGFs are pivotal regulators of angiogenesis and include 5 members in mammals: VEGF (or VEGF-A), placental growth factor, VEGF-B, VEGF-C and VEGF-D [19]. The VEGF-A signaling cascade via VEGF receptor-2 is considered to be the main angiogenic pathway [20, 21]. VEGF receptor-1 inhibits VEGF-mediated angiogenesis during development but enhances pathological angiogenesis when activated by placental growth factor and VEGF-B [22-24]. Both VEGF-C and VEGF-D facilitate lymphangiogenesis via VEGF receptor-3, although VEGF-C is the major player in both physiological and pathological lymphangiogenesis [25-27].

The correlation between VEGF-C and RA pathogenesis has been discussed previously [28]. Increased VEGF-C expression has been observed in the synovial lining of RA patients [29] and levels of VEGF-C expression reflect the severity of synovitis in early RA [30]. However, despite the recognized impact of VEGF-C on RA pathogenesis and the known prognostic value of VEGF-C SNPs for human disease, little is known about the potential association between VEGF-C SNPs and the risk of RA. In this study, we sought to determine the predictive capacity of VEGF-C SNPs as potential biomarkers for RA susceptibility.

\section{Materials and Methods}

\section{Patients and blood samples}

We collected whole blood samples $(3 \mathrm{~mL})$ from 210 patients diagnosed with RA at Dongyang People's Hospital, Zhejiang Province, China, and from 373 healthy voluntary donors without RA or any history of malignancy (control group) between 2007 and 2015. All the study participants provided written informed consent for the study, which was approved by the Dongyang People's Hospital Ethics Committee and Institutional Review Board (2015-YB002). Clinical and pathological characteristics of all participants were obtained from medical records, including age at disease onset and blood sampling data, gender, and treatment regimens. At baseline, serum samples were collected from all RA patients and analyzed for levels of anti-citrullinated protein antibodies (ACPAs), rheumatoid factor (RF), erythrocyte sedimentation rate (ESR) and C-reactive protein (CRP). Samples were deemed ACPA-positive if serum titers of anti-cyclic citrullinated peptide antibodies (anti-CCP2) were $\geq 17 \mathrm{IU} / \mathrm{mL}$ and RF-positive if immunoglobulin $\mathrm{M}(\mathrm{IgM}) \mathrm{RF}$ titers were $\geq 30 \mathrm{IU} / \mathrm{mL}$. All blood samples were stored at $-80^{\circ} \mathrm{C}$ for subsequent analysis.

\section{Selection of VEGF-C polymorphisms}

Five VEGF-C SNPs were selected from the intron of the VEGF-C gene. All SNPs had minor allele frequencies of greater than $5 \%$.

\section{Genomic DNA extraction}

Genomic DNA was extracted from leukocytes in the peripheral blood utilizing a QIAamp DNA blood kit (Qiagen, CA, USA), following the manufacturer's instructions. Extracted DNA was stored at $-20^{\circ} \mathrm{C}$ and prepared for genotyping by polymerase chain reaction (PCR) [31, 32].

\section{Genotyping by real-time PCR}

Five VEGF-C SNP probes were purchased from Applied Biosystems (CA, USA). The recognition of allelic discrimination for VEGF-C SNPs was conducted utilizing a QuantStudioTM 5 Real-Time PCR system, following the manufacturer's instructions. Data were analyzed with QuantStudio ${ }^{\mathrm{TM}}$ Design and Analysis Software (Applied Biosystems, CA, USA). PCR was performed in a total volume of 10 $\mu \mathrm{L}$, containing 20-70 ng genomic DNA, 1 U Taqman Genotyping Master Mix, and $0.25 \mu \mathrm{L}$ probes. The PCR protocol included an initial 10-min denaturation step at $95^{\circ} \mathrm{C}$, followed by 40 cycles of $95^{\circ} \mathrm{C}$ for $15 \mathrm{~s}$ and $60^{\circ} \mathrm{C}$ for $1 \mathrm{~min}[33,34]$.

\section{Statistical analysis}

Between-group differences were considered significant if $p$ values were less than 0.05 . Hardy-Weinberg equilibrium (HWE) was assessed using Chi-square goodness-of-fit tests for biallelic markers. Fisher's exact test was utilized to compare differences in demographic characteristics between the two groups. The odds ratios (ORs) and 95\% confidence intervals (CIs) for associations between genotype frequencies and the risk of RA or pertinent characteristics were estimated by multiple logistic regression models that controlled for age and gender. All data were analyzed using Statistical Analytic System software (v. 9.1, 2005; SAS Institute, Cary, NC, USA). 


\section{Results}

All of the study participants were of Chinese Han ethnicity. The mean age at blood sampling was $55.05 \pm 11.75$ years for the RA cohort and $42.08 \pm 19.02$ years for the controls $(p<0.001)$. The proportion of female participants was $82.9 \%$ in the RA cohort and $56.6 \%$ in the control cohort $(p<0.0001)$. The interval between the onset of RA and the blood sampling was $53.73 \pm 68.58$ months. At the time of blood sampling, $60.0 \%$ of the RA cohort were receiving TNF- $\alpha$ inhibitors, $43.3 \%$ were receiving methotrexate, and $45.7 \%$ were receiving prednisolone. The majority of RA patients were rheumatoid factor (RF)-positive $(85.2 \%)$ and anti-citrullinated protein antibody (ACPA)-positive (78.6\%) (Table 1 ).

Polymorphism frequencies for both cohorts are detailed in Table 2. All genotypes were in Hardy-Weinberg equilibrium $(p>0.05)$. The most frequent genotypes for SNPs rs7664413, rs11947611, rs1485766. rs2046463 and rs3775194 were C/C, A/G, $\mathrm{G} / \mathrm{T}, \mathrm{A} / \mathrm{A}$ and $\mathrm{G} / \mathrm{G}$ for the RA cohort and C/C, A/A, $\mathrm{G} / \mathrm{T}, \mathrm{A} / \mathrm{G}$, and $\mathrm{G} / \mathrm{G}$ for the controls, respectively. Having the A/G genotype of SNP rs11947611 significantly decreased the risk of developing RA disease, compared with having the A/A genotype (adjusted OR [AOR] $0.61 ; 95 \% \mathrm{CI}, 0.40$ to $0.92 ; p=$ 0.02).

RA disease occurred at the age of $<35$ years in 25 patients and at age $\geq 35$ years in 185 patients. Analyses of the data for any correlation between SNPs and RA onset before 35 years of age revealed that having the SNP rs7664413 C/T genotype was associated with an $\sim 80 \%$ lower likelihood of RA compared with having the wild-type C/C genotype (AOR $0.21 ; 95 \% \mathrm{CI}, 0.06$ to $0.78 ; p=0.02)$, which was also the case for patients who had the SNP rs2046463 A/G genotype compared with those who had the wild-type A/A genotype (AOR 0.20; 95\% CI, 0.05 to $0.74 ; p=0.02$ ), while those who had the SNP rs11947611 non-A/A genotype (A/G, G/G) had a $\sim 3$-fold higher risk of developing RA compared with those who had the A/A genotype (AOR 3.23; 95\% CI, 1.04 to 10.06; $p=0.04$ ) (Table 3).

Analyses failed to find any correlations between serum levels of RA biomarkers (RF, ACPA, ESR and CRP) and the SNP rs11947611 at the time of blood sampling (Table 4). In an analysis of SNPs and medication requirements, patients who had the non-C/C (C/T, T/T) genotype of the SNP rs7664413 had a higher than 2-fold risk of requiring methotrexate as compared with patients who had the $\mathrm{C} / \mathrm{C}$ genotype (AOR 2.07; 95\% CI, 1.17 to 3.68; $p=$ $0.01)$, as did those who had the non-A/A (A/G, G/G) genotype of the rs2046463 SNP as compared with patients who had the A/A genotype (AOR 2.23; 95\% $\mathrm{CI}, 1.25$ to $3.98 ; p=0.01)$, while patients who had the non-G/G (G/C, C/C) genotype of the rs3775194 SNP had a significantly reduced risk of requiring steroids compared with patients who had the G/G genotype (AOR 0.39; 95\% CI, 0.19 to $0.79 ; p=0.01$ ) (Table 5).

Table 1. Demographic characteristics of the study population.

\begin{tabular}{|c|c|c|c|c|c|}
\hline \multirow[t]{2}{*}{ Variables } & & \multirow{2}{*}{$\begin{array}{l}\text { Healthy controls }(n=373) \\
\mathbf{N}(\%)\end{array}$} & \multirow{2}{*}{$\begin{array}{l}\text { RA patients }(\mathrm{n}=210) \\
\mathrm{N}(\%)\end{array}$} & \multirow[t]{2}{*}{ OR $\quad(95 \% \mathrm{CI})$} & \multirow[t]{2}{*}{$p$ value } \\
\hline & & & & & \\
\hline Age (years) (mean \pm SD) & & $42.08 \pm 19.02$ & $55.05 \pm 11.75$ & & $<0.0001$ \\
\hline \multicolumn{6}{|l|}{ Sex } \\
\hline Female & & $211(56.6)$ & $174(82.9)$ & 1 & \\
\hline Male & & $162(43.4)$ & $36(17.1)$ & $0.27(0.18$ to 0.41$)$ & $<0.0001$ \\
\hline \multicolumn{6}{|l|}{ RF } \\
\hline \multirow[t]{2}{*}{ seropositive } & - & ND & $31(14.8)$ & & \\
\hline & + & ND & $179(85.2)$ & & \\
\hline \multicolumn{6}{|l|}{ ACPA } \\
\hline & - & ND & $45(21.4)$ & & \\
\hline & + & ND & $165(78.6)$ & & \\
\hline \multicolumn{6}{|l|}{ Anti-TNF } \\
\hline & - & ND & $85(40.0)$ & & \\
\hline & + & ND & $126(60.0)$ & & \\
\hline \multicolumn{6}{|l|}{ Methotrexate } \\
\hline & - & ND & $119(56.7)$ & & \\
\hline & + & ND & $91(43.3)$ & & \\
\hline \multicolumn{6}{|l|}{ Prednisolone } \\
\hline & - & ND & $114(54.3)$ & & \\
\hline & + & ND & $96(45.7)$ & & \\
\hline ESR (mean \pm SD) & & & $30.54 \pm 24.82$ & & \\
\hline$<20$ & & ND & $96(45.7)$ & & \\
\hline$\geq 20$ & & ND & $114(54.3)$ & & \\
\hline $\mathrm{CRP}($ mean $\pm \mathrm{SD})$ & & & $22.68 \pm 82.31$ & & \\
\hline$<8$ & & ND & $128(61.0)$ & & \\
\hline$\geq 8$ & & ND & $82(39.0)$ & & \\
\hline RA duration, months (mean $\pm \mathrm{SD}$ ) & & ND & $53.73 \pm 68.58$ & & \\
\hline
\end{tabular}


Table 2. VEGF-C genotyping frequencies in cases and controls and the association with risk of RA.

\begin{tabular}{|c|c|c|c|c|c|c|c|c|c|}
\hline \multirow[t]{2}{*}{ Variables } & Control(n=373) & Case $(n=210)$ & \multirow[t]{2}{*}{ OR } & \multirow[t]{2}{*}{$(95 \%$ CI $)$} & \multirow[t]{2}{*}{$P$ Value } & \multirow[t]{2}{*}{ AOR $^{\mathbf{a}}$} & \multirow[t]{2}{*}{$(95 \% \mathrm{CI})$} & \multirow[t]{2}{*}{$P$ Value } & \multirow[t]{2}{*}{ HWEb } \\
\hline & N (\%) & N (\%) & & & & & & & \\
\hline rs7664413 & & & & & & & & & $0.03 / 0.98$ \\
\hline $\mathrm{CC}$ & $182(48.8)$ & $98(46.7)$ & 1 & & & 1 & & & \\
\hline $\mathrm{CT}$ & $141(37.8)$ & $92(43.8)$ & 1.21 & $(0.85-1.74)$ & 0.29 & 1.25 & $(0.83-1.90)$ & 0.25 & \\
\hline TT & $50(13.4)$ & $20(9.5)$ & 0.74 & $(0.42-1.32)$ & 0.31 & 0.56 & $(0.29-1.07)$ & 0.08 & \\
\hline $\mathrm{CT}+\mathrm{TT}$ & $191(51.2)$ & $112(53.33)$ & 1.09 & $(0.78-1.53)$ & 0.62 & 1.04 & $(0.71-1.53)$ & 0.84 & \\
\hline rs11947611 & & & & & & & & & $0.95 / 0.10$ \\
\hline AA & $161(43.2)$ & $110(52.4)$ & 1 & & & 1 & & & \\
\hline AG & $166(44.5)$ & $75(35.7)$ & 0.66 & $(0.46-0.95)$ & 0.03 & 0.61 & $(0.40-0.92)$ & 0.02 & \\
\hline GG & $46(12.3)$ & 25 (11.9) & 0.8 & $(0.46-1.37)$ & 0.41 & 0.74 & (040-1.39) & 0.34 & \\
\hline $\mathrm{AG}+\mathrm{GG}$ & $212(56.8)$ & $100(47.6)$ & 0.69 & $(0.49-0.97)$ & 0.03 & 0.64 & $(0.43-0.94)$ & 0.03 & \\
\hline rs1485766 & & & & & & & & & $0.47 / 0.06$ \\
\hline GG & $111(29.8)$ & $47(22.4)$ & 1 & & & 1 & & & \\
\hline GT & $174(46.6)$ & $104(49.5)$ & 1.12 & $(0.76-1.68)$ & 0.56 & 0.98 & $(0.62-1.55)$ & 0.93 & \\
\hline TT & $88(23.6)$ & $59(28.1)$ & 1.01 & $(0.63-1.62)$ & 0.98 & 1.06 & $(0.62-1.81)$ & 0.86 & \\
\hline $\mathrm{GT}+\mathrm{TT}$ & $262(70.24)$ & 151 (71.9) & 1.08 & $(0.75-1.58)$ & 0.67 & 1.01 & $(0.66-1.54)$ & 0.98 & \\
\hline rs2046463 & & & & & & & & & $0.03 / 0.82$ \\
\hline AA & $181(48.5)$ & $94(44.8)$ & 1 & & & 1 & & & \\
\hline AG & $141(37.8)$ & $96(45.7)$ & 1.31 & $(0.92-1.88)$ & 0.34 & 1.35 & $(0.89-2.05)$ & 0.15 & \\
\hline GG & $51(13.7)$ & $20(9.5)$ & 0.76 & $(0.43-1.34)$ & 0.14 & 0.57 & $(0.30-1.10)$ & 0.09 & \\
\hline $\mathrm{AG}+\mathrm{GG}$ & $192(51.5)$ & $116(55.2)$ & 1.16 & $(0.83-1.63)$ & 0.38 & 1.11 & $(0.76-1.64)$ & 0.59 & \\
\hline rs3775194 & & & & & & & & & $0.99 / 0.97$ \\
\hline GG & $311(83.4)$ & $168(80.0)$ & 1 & & & 1 & & & \\
\hline CG & 59 (15.8) & $40(19.0)$ & 1.26 & $(0.81-1.96)$ & 0.32 & 1.38 & $(0.82-2.32)$ & 0.22 & \\
\hline $\mathrm{CC}$ & $3(0.8)$ & $2(1.0)$ & 1.23 & $(0.20-7.46)$ & 0.82 & 1.17 & $(0.17-7.96)$ & 0.87 & \\
\hline $\mathrm{CG}+\mathrm{CC}$ & 62 (16.6) & $42(20.0)$ & 1.25 & $(0.81-1.94)$ & 0.31 & 1.37 & $(0.83-2.27)$ & 0.22 & \\
\hline
\end{tabular}

a Logistic regression with adjustment for age, gender. ${ }^{\mathrm{b}}$ Control/Case Hardy-Weinberg equilibrium test.

Table 3. The association with VEGF-C genotyping frequencies and age onset of RA.

\begin{tabular}{|c|c|c|c|c|c|c|}
\hline & \multicolumn{2}{|c|}{ Age-onset $<35$ years } & \multirow[t]{2}{*}{ OR (95 \% CI) } & \multirow[t]{2}{*}{$p$ Value } & \multirow[t]{2}{*}{$\operatorname{AOR}^{a}(95 \% \mathrm{CI})$} & \multirow[t]{2}{*}{$p$ Value } \\
\hline & $(n=185) N(\%)$ & $(n=25) N(\%)$ & & & & \\
\hline Age, year (mean $\pm S D)$ & $39.28 \pm 11.77$ & $57.18 \pm 10.02$ & & $<0.0001$ & & \\
\hline \multicolumn{7}{|l|}{ rs7664413 } \\
\hline $\mathrm{CC}$ & $82(44.3)$ & $16(64.0)$ & 1 & & 1 & \\
\hline $\mathrm{CT}$ & $85(46.0)$ & $7(28.0)$ & $0.42(0.17-1.08)$ & 0.07 & $0.21(0.06-.078)$ & 0.02 \\
\hline $\mathrm{TT}$ & $18(9.7)$ & $2(8.0)$ & $0.57(0.12-2.70)$ & 0.48 & $0.4(0.06-2.67)$ & 0.34 \\
\hline $\mathrm{CT}+\mathrm{TT}$ & $103(55.7)$ & $9(36.0)$ & $0.45(0.19-1.07)$ & 0.07 & $0.24(0.07-0.80)$ & 0.02 \\
\hline \multicolumn{7}{|l|}{ rs11947611 } \\
\hline AA & $101(54.6)$ & $9(36.0)$ & 1 & & 1 & \\
\hline AG & $64(34.6)$ & $11(44.0)$ & $1.93(0.76-4.91)$ & 0.17 & $3.26(0.96-11.07)$ & 0.06 \\
\hline GG & $20(10.8)$ & $5(20.0)$ & $2.81(0.85-9.26)$ & 0.09 & $3.16(0.61-16.46)$ & 0.17 \\
\hline$A G+G G$ & $84(45.4)$ & $16(64.0)$ & $2.14(0.90-5.08)$ & 0.09 & $3.23(1.04-10.06)$ & 0.04 \\
\hline \multicolumn{7}{|l|}{ rs1485766 } \\
\hline GG & $55(29.7)$ & $4(16.0)$ & 1 & & 1 & \\
\hline GT & $93(50.3)$ & $11(44.0)$ & $1.63(0.49-5.36)$ & 0.42 & $2.28(0.53-9.82)$ & 0.27 \\
\hline $\mathrm{TT}$ & $37(20.0)$ & $10(40.0)$ & $3.72(1.08-12.70)$ & 0.04 & $3.67(0.80-16.96)$ & 0.09 \\
\hline $\mathrm{GT}+\mathrm{TT}$ & $130(70.3)$ & 151 (71.9) & $2.22(0.73-6.77)$ & 0.16 & $2.79(0.71-10.93)$ & 0.14 \\
\hline \multicolumn{7}{|l|}{ rs2046463 } \\
\hline AA & $78(42.2)$ & $16(64.0)$ & 1 & & 1 & \\
\hline AG & $89(48.1)$ & $7(28.0)$ & $0.38(0.15-0.98)$ & 0.04 & $0.2(0.05-0.74)$ & 0.02 \\
\hline GG & $18(9.7)$ & $2(8.0)$ & $0.54(0.11-0.57)$ & 0.44 & $0.38(0.05-0.60)$ & 0.33 \\
\hline $\mathrm{AG}+\mathrm{GG}$ & $107(57.8)$ & $9(36.0)$ & $0.41(0.17-0.98)$ & 0.04 & $0.23(0.07-0.76)$ & 0.02 \\
\hline \multicolumn{7}{|l|}{ rs3775194 } \\
\hline GG & $146(78.9)$ & $22(88.0)$ & 1 & & 1 & \\
\hline CG & $37(20.0)$ & $3(12.0)$ & $0.54(0.15-1.89)$ & 0.33 & $0.44(0.09-2.18)$ & 0.32 \\
\hline $\mathrm{CC}$ & $2(1.1)$ & $0(0.0)$ & & & & \\
\hline $\mathrm{CG}+\mathrm{CC}$ & $39(21.1)$ & $2(12.0)$ & $0.51(0.15-1.79)$ & 0.29 & 0.39 & 0.24 \\
\hline
\end{tabular}

a Logistic regression with adjustment for age, gender.

\section{Discussion}

Although the advent of biological-based therapies has helped many patients with RA to achieve good disease control, some remain treatment-refractory [35]. It is therefore critical that investigations continue to explore the pathogenesis of RA. One promising avenue of research is the identification of RA-related SNPs, which will also enable risk stratification of patients for treatment [36]. VEGF-C SNPs have prognostic value in various diseases [17-19]. A Taiwanese study has reported that 
the VEGF-C rs1485766 polymorphism appears to contribute to the risk of urothelial cell carcinoma (UCC) [17] . That study also found that smokers with certain genetic variants of $V E G F-C$ were more likely to develop UCC and larger-sized tumors than smokers with wild-type homozygotes. Another Taiwanese study has reported that VEGF-C rs7664413 and rs2046463 polymorphisms and either of 2 haplotypes of $5 \mathrm{VEGF}-\mathrm{C}$ combined were related to the risk of oral cancer [18]. The study researchers also found that among male smokers, VEGF-C variant carriers who also chewed betel quid were 14-5-24.2-fold more likely to have oral cancer compared to VEGF-C wild-type carriers who did not chew betel quid. Conversely, in the cohort of men who chewed betel quid, those carrying the VEGF-C polymorphism who also smoked were 2.7-18.2-fold to have oral cancer compared to those who carried the wild type but did not smoke. Interestingly, Japanese research has found that having a low VEGF-C level is significantly and inversely associated with all-cause mortality among patients with suspected or known coronary artery disease, which contrasts with the fact that high $V E G F-C$ levels are apparently associated with poor prognosis in patients with malignancies [19].

Despite the evidence inferring a role for VEGF-C in the pathogenesis of RA and the prognostic capacity of VEGF-C SNPs in human diseases, few studies have investigated the relationship between VEGF-C SNPs and risk of RA development and progression. We therefore sought to determine the prognostic capacity of VEGF-C SNPs in predicting RA onset. To the best of our knowledge, our study is the first to identify that the VEGF-C rs7664413, rs11947611, rs1485766, rs2046463, and rs3775194 polymorphisms are related to RA development. We found that having the A/G genotype of SNP rs11947611 exerted a significantly protective effect against developing RA $(p=0.02)$.

Table 4. Clinical biochemical status and VEGF-C rs 11947611 genotypic frequencies in RA Patients*

\begin{tabular}{|c|c|c|c|c|c|c|c|}
\hline \multirow{2}{*}{\multicolumn{2}{|c|}{ Variables }} & AA $(n=110)$ & $A G+G G(n=100)$ & \multirow[t]{2}{*}{ OR (95\% CI) } & \multirow[t]{2}{*}{$p$ value } & \multirow[t]{2}{*}{ AORa(95\% CI) } & \multirow[t]{2}{*}{$p$ value } \\
\hline & & $\mathbf{N}(\%)$ & $\mathbf{N}(\%)$ & & & & \\
\hline \multicolumn{8}{|c|}{ rs11947611 } \\
\hline \multirow[t]{2}{*}{ RF } & Negative & $16(14.5)$ & $15(15.0)$ & 1 & & 1 & \\
\hline & Positive & $94(85.5)$ & $85(85.0)$ & $0.97(0.45-2.07)$ & 0.93 & $0.97(0.45-2.09)$ & 0.94 \\
\hline \multirow[t]{2}{*}{ ACPA } & Negative & $25(22.7)$ & $20(20.0)$ & 1 & & & \\
\hline & Positive & 85 (77.3) & $80(80.0)$ & $1.18(0.61-2.28)$ & 0.63 & $1.15(0.59-2.25)$ & 0.67 \\
\hline \multirow[t]{2}{*}{ ESR } & $<20$ & $50(45.5)$ & $46(46.0)$ & 1 & & 1 & \\
\hline & $\geq 20$ & $60(54.5)$ & $54(54.0)$ & $0.98(0.57-1.69)$ & 0.94 & $0.97(0.56-1.68)$ & 0.92 \\
\hline \multirow[t]{2}{*}{ CRP } & $<8$ & 65 (59.1) & $63(63.0)$ & 1 & & 1 & \\
\hline & $\geq 8$ & $45(40.9)$ & $37(37.0)$ & $0.85(0.49-1.48)$ & 0.56 & $0.86(0.49-1.51)$ & 0.6 \\
\hline
\end{tabular}

${ }^{*} \mathrm{RF}=$ rheumatoid factor; $\mathrm{ACPA}=$ anti-citrullinated protein antibodies; $\mathrm{ESR}=$ erythrocyte sedimentation rate; $\mathrm{CRP}=\mathrm{C}$-reactive protein; Logistic regression with adjustment for age, gender.

Table 5. The association with VEGF-C genotyping frequencies and RA medication.

\begin{tabular}{|c|c|c|c|c|c|c|c|}
\hline Variables & & $\mathbf{N}(\%)$ & N (\%) & OR $(95 \% \mathrm{CI})$ & $P$ Value & AORa (95\% CI) & $P$ Value \\
\hline rs7664413 & & $C C(n=98)$ & $\mathrm{CT}+\mathrm{TT}(\mathrm{n}=112)$ & & & & \\
\hline \multirow[t]{2}{*}{ Anti-TNF } & - & $53(54.1)$ & $73(65.2)$ & 1 & & 1 & \\
\hline & + & 45 (45.9) & $39(34.8)$ & $0.63(0.36-1.10)$ & 0.1 & $0.65(0.37-1.14)$ & 0.13 \\
\hline \multirow[t]{2}{*}{ Methotrexate } & - & $51(52.0)$ & $40(35.7)$ & 1 & & 1 & \\
\hline & + & $47(48.0)$ & $72(64.3)$ & $1.95(1.12-3.40)$ & 0.02 & $2.07(1.17-3.68)$ & 0.01 \\
\hline \multirow[t]{2}{*}{ Prednisolone } & - & $49(50.0)$ & $47(42.0)$ & 1 & & 1 & \\
\hline & + & $49(50.0)$ & $65(58.0)$ & $1.38(0.80-2.34)$ & 0.24 & $1.36(0.78-2.35)$ & 0.28 \\
\hline rs2046463 & & AA $(n=94)$ & AG+GG $(n=116)$ & & & & \\
\hline \multirow[t]{2}{*}{ Anti-TNF } & - & $50(53.2)$ & $76(65.5)$ & 1 & & 1 & \\
\hline & + & $44(46.8)$ & $40(34.5)$ & $0.60(0.34-1.04)$ & 0.07 & $0.62(0.36-1.10)$ & 0.1 \\
\hline \multirow[t]{2}{*}{ Methotrexate } & - & $50(53.2)$ & $41(35.3)$ & 1 & & 1 & \\
\hline & + & $44(46.8)$ & $75(64.7)$ & 2.08(1.19-3.62) & 0.01 & $2.23(1.25-3.98)$ & 0.01 \\
\hline \multirow[t]{2}{*}{ Prednisolone } & - & $48(51.1)$ & $48(41.4)$ & 1 & & 1 & \\
\hline & + & $46(48.9)$ & $68(58.6)$ & $1.48(0.86-2.56)$ & 0.16 & $1.44(0.83-2.49)$ & 0.2 \\
\hline rs3775194 & & GG $(n=168)$ & $\mathrm{GC}+\mathrm{CC}(\mathrm{n}=42)$ & & & & \\
\hline \multirow[t]{2}{*}{ Anti-TNF } & - & $102(60.7)$ & $24(57.1)$ & 1 & & 1 & \\
\hline & + & $66(39.3)$ & 18 (42.9) & $1.15(0.58-2.30)$ & 0.67 & $1.13(0.57-2.27)$ & 0.73 \\
\hline \multirow[t]{2}{*}{ Methotrexate } & - & $74(44.1)$ & $17(40.5)$ & 1 & & 1 & \\
\hline & + & $94(55.9)$ & 25 (59.5) & $1.16(0.57-2.30)$ & 0.68 & $1.27(0.62-2.59)$ & 0.51 \\
\hline \multirow[t]{2}{*}{ Prednisolone } & - & $69(41.1)$ & $27(64.3)$ & 1 & & 1 & \\
\hline & + & 99 (58.9) & $15(35.7)$ & $0.39(0.19-0.78)$ & 0.01 & $0.39(0.19-0.79)$ & 0.01 \\
\hline
\end{tabular}

a Logistic regression with adjustment for age, gender. 
When we analyzed associations between the 5 VEGF-C SNPs and age of RA onset, we found a significantly protective effect for the heterozygous genotype (C/T) of SNP rs7664413 for the development of RA disease before 35 years of age, which was also the case for patients who had the A/G genotype of rs2046463 ( $p=0.02$ for each comparison with the wild-type genotypes of each polymorphism). Conversely, RA patients who had the non-A/A genotype (A/G, G/G) of SNP rs11947611 had a substantially higher risk of developing RA before the age of 35 years compared with their wild-type counterparts $(p=0.04)$. In analyses of requirements for RA medications, patients with the non-C/C genotype $(C / T, T / T)$ of rs7664413 were significantly more likely to require methotrexate, as were those with the non-A/A genotype (A/G, G/G) of rs2046463 $(p=0.01$ for both comparisons vs the wild-type genotypes of each polymorphism, respectively), while RA patients who had the non-G/G genotype (G/C, $\mathrm{C} / \mathrm{C}$ ) of rs3775194 were significantly less likely to require steroidal treatment as compared with their wild-type counterparts $(p=0.01)$. Further explorations are warranted into correlations between clinical profiles of RA disease activity and genetic variants of the VEGF-C gene.

A major limitation of our study is that our findings might merely reflect a cross-sectional relationship instead of actual causality. This is a common limitation of similar studies and could potentially be overcome by more in-depth investigations analyzing the relationships between all known SNP elements. Besides, some important clinical parameters are not ubiquitously available from the existing medical records, such as disease activity score -28 (DAS-28), Larsen score, and visual analogue scale (VAS). More comprehensive documentation of clinical parameters should be warranted in the future studies.

In conclusion, our study offers novel insights into VEGF-C SNPs in regard to RA susceptibility. We found that A/G genotype of SNP rs11947611 was a protective factor for RA development. This is the first study to show associations between VEGF-C polymorphisms and RA susceptibility, early age of onset and treatment regimens. Thus, VEGF-C appears to be a diagnostic marker and therapeutic target for RA therapy; therapeutic agents that directly or indirectly regulate $V E G F-C$ activity may prove promising in the treatment of RA disease.

\section{Acknowledgments}

The authors are thankful for the editing by Iona J. MacDonald in China Medical University. This work was supported by a grant from Ministry of Science and Technology of Taiwan (MOST 107-2320-B-039019-MY3) and China Medical University (CMU 107-ASIA-09).

\section{Competing Interests}

The authors have declared that no competing interest exists.

\section{References}

1. Dai C, Kuo SJ, Zhao J, Jin L, Kang L, Wang L, et al. Correlation between genetic polymorphism of angiopoietin-2 gene and clinical aspects of rheumatoid arthritis. Int J Med Sci. 2019; 16: 331-6.

2. MacDonald IJ, Liu SC, Su CM, Wang YH, Tsai CH, Tang CH. Implications of Angiogenesis Involvement in Arthritis. International journal of molecular sciences. 2018; 19.

3. Su CM, Huang CY, Tang $\mathrm{CH}$. Characteristics of resistin in rheumatoid arthritis angiogenesis. Biomarkers in medicine. 2016; 10: 651-60.

4. Liu SC, Tsai $\mathrm{CH}, \mathrm{Wu}$ TY, Tsai CH, Tsai FJ, Chung JG, et al. Soya-cerebroside reduces IL-1 beta-induced MMP-1 production in chondrocytes and inhibits cartilage degradation: implications for the treatment of osteoarthritis. Food Agr Immunol. 2019; 30: 620-32.

5. Kuo SJ, Huang CC, Tsai CH, Hsu HC, Su CM, Tang CH. Chemokine C-C Motif Ligand 4 Gene Polymorphisms Associated with Susceptibility to Rheumatoid Arthritis. BioMed research international. 2018; 2018: 9181647.

6. Wang $\mathrm{LH}, \mathrm{Wu} \mathrm{MH}$, Chen PC, Su CM, Xu G, Huang CC, et al. Prognostic significance of high-mobility group box protein 1 genetic polymorphisms in rheumatoid arthritis disease outcome. Int J Med Sci. 2017; 14: 1382-8.

7. Tang CH. Research of Pathogenesis and Novel Therapeutics in Arthritis. International journal of molecular sciences. 2019; 20.

8. Sokka T, Abelson B, Pincus T. Mortality in rheumatoid arthritis: 2008 update. Clin Exp Rheumatol. 2008; 26: S35-61.

9. Chung IM, Ketharnathan S, Thiruvengadam M, Rajakumar G. Rheumatoid Arthritis: The Stride from Research to Clinical Practice. Int J Mol Sci. 2016; 17.

10. Taylor JC, Bongartz T, Massey J, Mifsud B, Spiliopoulou A, Scott IC, et al. Genome-wide association study of response to methotrexate in early rheumatoid arthritis patients. The pharmacogenomics journal. 2018; 18: 528-38.

11. Yang WH, Wang SJ, Chang YS, Su CM, Yang SF, Tang CH. Association of Resistin Gene Polymorphisms with Oral Squamous Cell Carcinoma Progression and Development. Biomed Res Int. 2018; 2018: 9531315.

12. Hu WW, Chen PC, Chen JM, Wu YM, Liu PY, Lu CH, et al. Periostin promotes epithelial-mesenchymal transition via the MAPK/miR-381 axis in lung cancer. Oncotarget. 2017; 8: 62248-60.

13. Chanock S. Candidate genes and single nucleotide polymorphisms (SNPs) in the study of human disease. Disease markers. 2001; 17: 89-98.

14. Yang MD, Lin KC, Lu MC, Jeng LB, Hsiao CL, Yueh TC, et al. Contribution of matrix metalloproteinases-1 genotypes to gastric cancer susceptibility in Taiwan. BioMedicine. 2017; 7: 10.

15. Berczi B, Gerencser G, Farkas N, Hegyi P, Veres G, Bajor J, et al. Association between AIRE gene polymorphism and rheumatoid arthritis: a systematic review and meta-analysis of case-control studies. Sci Rep. 2017; 7: 14096.

16. Suzuki A, Yamamoto K. From genetics to functional insights into rheumatoid arthritis. Clin Exp Rheumatol. 2015; 33: S40-3.

17. Tung MC, Hsieh MJ, Wang SS, Yang SF, Chen SS, Wang SW, et al. Associations of VEGF-C genetic polymorphisms with urothelial cell carcinoma susceptibility differ between smokers and non-smokers in Taiwan. PLoS One. 2014; 9: e91147.

18. Chien $\mathrm{MH}$, Liu YF, Hsin $\mathrm{CH}$, Lin $\mathrm{CH}$, Shih $\mathrm{CH}$, Yang SF, et al. Impact of VEGF-C gene polymorphisms and environmental factors on oral cancer susceptibility in Taiwan. PLoS One. 2013; 8: e60283.

19. Wada H, Suzuki M, Matsuda M, Ajiro Y, Shinozaki T, Sakagami S, et al. VEGF-C and Mortality in Patients With Suspected or Known Coronary Artery Disease. J Am Heart Assoc. 2018; 7: e010355.

20. Stitzlein L, Rao P, Dudley R. Emerging oral VEGF inhibitors for the treatment of renal cell carcinoma. Expert opinion on investigational drugs. 2019; 28 : 121-30.

21. Karaman S, Leppanen VM, Alitalo K. Vascular endothelial growth factor signaling in development and disease. Development. 2018; 145.

22. Chen CY, Su CM, Hsu CJ, Huang CC, Wang SW, Liu SC, et al. CCN1 Promotes VEGF Production in Osteoblasts and Induces Endothelial Progenitor Cell Angiogenesis by Inhibiting miR-126 Expression in Rheumatoid Arthritis. Journal of bone and mineral research : the official journal of the American Society for Bone and Mineral Research. 2017; 32: 34-45.

23. Mercurio AM. VEGF/Neuropilin Signaling in Cancer Stem Cells. Int J Mol Sci. $2019 ; 20$.

24. Lee HP, Chen PC, Wang SW, Fong YC, Tsai CH, Tsai FJ, et al. Plumbagin suppresses endothelial progenitor cell-related angiogenesis in vitro and in vivo. J Funct Foods. 2019; 52: 537-44.

25. Joukov V, Pajusola K, Kaipainen A, Chilov D, Lahtinen I, Kukk E, et al. A novel vascular endothelial growth factor, VEGF-C, is a ligand for the Flt4 
(VEGFR-3) and KDR (VEGFR-2) receptor tyrosine kinases. EMBO J. 1996; 15: 290-98.

26. Su CM, Tang $\mathrm{CH}$, Chi MJ, Lin CY, Fong YC, Liu YC, et al. Resistin facilitates VEGF-C-associated lymphangiogenesis by inhibiting miR-186 in human chondrosarcoma cells. Biochem Pharmacol. 2018; 154: 234-42.

27. Lien MY, Tsai HC, Chang AC, Tsai MH, Hua CH, Wang SW, et al. Chemokine CCL4 Induces Vascular Endothelial Growth Factor C Expression and Lymphangiogenesis by miR-195-3p in Oral Squamous Cell Carcinoma. Front Immunol. 2018; 9: 412.

28. Wauke K, Nagashima M, Ishiwata T, Asano G, Yoshino S. Expression and localization of vascular endothelial growth factor-C in rheumatoid arthritis synovial tissue. J Rheumatol. 2002; 29: 34-8.

29. Paavonen K, Mandelin J, Partanen T, Jussila L, Li TF, Ristimaki A, et al. Vascular endothelial growth factors $\mathrm{C}$ and D and their VEGFR-2 and 3 receptors in blood and lymphatic vessels in healthy and arthritic synovium. J Rheumatol. 2002; 29: 39-45.

30. Kelly S, Bombardieri M, Humby F, Ng N, Marrelli A, Riahi S, et al. Angiogenic gene expression and vascular density are reflected in ultrasonographic features of synovitis in early Rheumatoid Arthritis: an observational study. Arthritis Res Ther. 2015; 17: 58 .

31. Hu GN, Tzeng HE, Chen PC, Wang CQ, Zhao YM, Wang Y, et al. Correlation between CCL4 gene polymorphisms and clinical aspects of breast cancer. Int J Med Sci. 2018; 15: 1179-86.

32. Hu WW, Tang $\mathrm{CH}$, Sun $\mathrm{Y}$, Lu TT, Jiang $\mathrm{P}, \mathrm{Wu}$ YM, et al. Correlation between resistin gene polymorphism and clinical aspects of lung cancer. Medicine. 2017; 96: e9485.

33. Wang L, Tang $\mathrm{CH}$, Lu T, Sun $\mathrm{Y}, \mathrm{Xu}$ G, Huang $\mathrm{CC}$, et al. Resistin polymorphisms are associated with rheumatoid arthritis susceptibility in Chinese Han subjects. Medicine. 2018; 97: e0177.

34. Lien MY, Lin CW, Tsai HC, Chen YT, Tsai MH, Hua CH, et al. Impact of CCL4 gene polymorphisms and environmental factors on oral cancer development and clinical characteristics. Oncotarget. 2017; 8: 31424-34.

35. Emery P. Optimizing outcomes in patients with rheumatoid arthritis and an inadequate response to anti-TNF treatment. Rheumatology. 2012; 51 Suppl 5: v22-30.

36. Viatte S, Barton A. Genetics of rheumatoid arthritis susceptibility, severity, and treatment response. Semin Immunopathol. 2017; 39: 395-408. 